\title{
CHANGES IN EDGE AND SCRAPE-OFF LAYER PLASMA BEHAVIOR DUE TO VARIATION IN MAGNETIC BALANCE IN DIII-D
}

\author{
by \\ T.W. PETRIE, J.G. WATKINS, L.R. BAYLOR, N.H. BROOKS, \\ M.E. FENSTERMACHER, A.W. HYATT, G.L. JACKSON, C.J. LASNIER, \\ A.W. LEONARD, A.YU. PIGAROV, M.E. RENSINK, T.D. ROGNLIEN, \\ M.J. SCHAFFER, N.S. WOLF, and the DIII-D TEAM
}




\section{DISCLAIMER}

This report was prepared as an account of work sponsored by an agency of the United States Government. Neither the United States Government nor any agency thereof, nor any of their employees, makes any warranty, express or implied, or assumes any legal liability or responsibility for the accuracy, completeness, or usefulness of any information, apparatus, product, or process disclosed, or represents that its use would not infringe privately owned rights. Reference herein to any specific commercial product, process, or service by trade name, trademark, manufacturer, or otherwise, does not necessarily constitute or imply its endorsement, recommendation, or favoring by the United States Government or any agency thereof. The views and opinions of authors expressed herein do not necessarily state or reflect those of the United States Government or any agency thereof. 
GA-A23989

\title{
CHANGES IN EDGE AND SCRAPE-OFF LAYER PLASMA BEHAVIOR DUE TO VARIATION IN MAGNETIC BALANCE IN DIII-D
}

by

T.W. PETRIE, J.G. WATKINS, † L.R. BAYLOR, N.H. BROOKS, M.E. FENSTERMACHER, $\diamond$ A.W. HYATT, G.L. JACKSON, C.J. LASNIER, $\diamond$ A.W. LEONARD, A.YU. PIGAROV, $\triangle$ M.E. RENSINK, $\diamond$ T.D. ROGNLIEN, $\diamond$ M.J. SCHAFFER, N.S. WOLF, $\diamond$ and the DIII-D TEAM

\author{
†Sandia National Laboratories \\ ¥0ak Ridge National Laboratory \\ $\checkmark$ Lawrence Livermore National Laboratory \\ $\Delta$ University of California, San Diego
}

This is a preprint of a paper presented at the 15th International Conference on Plasma Surface Interactions in Controlled Fusion Devices, May 27-31, 2002, in Gifu, Japan, and to be published in the Proceedings.

\author{
Work supported by \\ the U.S. Department of Energy \\ under Contracts DE-AC03-99ER54463 DE-AC04-94AL85000, \\ DE-AC05-000R22725, W-7405-ENG-48, and Grant DE-FG03-95ER54294
}

GA PROJECT 30033

JUNE 2002 


\begin{abstract}
Changes in the divertor magnetic balance in DIII-D H-mode plasmas affects core, edge, and divertor plasma behavior. Both the pedestal density $\mathrm{n}_{\mathrm{e}, \mathrm{PED}}$ and plasma stored energy $\mathrm{W}_{\mathrm{T}}$ were sensitive to changes in magnetic balance near the double-null (DN) configuration, e.g., both decreased 20\%-30\% when the DN shifted to a slightly unbalanced DN, where the $\mathbf{B} \times \nabla \mathrm{B}$ drift direction pointed away from the main X-point. Recycling at each of the four divertor targets was sensitive to changes in magnetic balance and the $\mathbf{B} \times \nabla \mathbf{B}$ drift direction. The poloidal distribution of the recycling in $\mathrm{DN}$ is in qualitative agreement with the predictions of UEDGE modeling with particle drifts included. The particle flux at the inner divertor target is shown to be much more sensitive to magnetic balance than the particle flux at the outer divertor target near the DN shape. These results suggest possible advantages and drawbacks for balanced DN operation.
\end{abstract}




\section{INTRODUCTION}

Plasma performance in tokamaks generally improves with increased shaping of the plasma cross section. For example, higher values of both energy confinement time and plasma beta are more readily obtained, when the plasma shape becomes increasingly "triangular," i.e., when the radial location of the $\mathrm{X}$-points are at higher magnetic field [1]. Because higher overall triangularity is achieved more naturally in the double-null (DN) shape than in a single-null (SN) shape, the DN configuration is attractive for future high performance tokamaks.

Previous studies at the DIII-D facility have found that changing the magnetic balance of the plasma shape very close to DN affected both the heat- and particle flux distributions at the divertor targets [2,3]. For example, sharply reduced power flow to the inner target(s) occurred, when the plasma shape changed from SN to DN. Moreover, for the balanced DN, we found no symmetry between the upper and lower outer divertors in either the heat flux or particle flux. Analysis with UEDGE [4], a 2-D fluid modeling edge transport code, indicates that such asymmetries may be the result of a complicated interplay of particle drifts at the edge of the core plasma [5,6], e.g., the ion $\nabla \mathbf{B}$ drift (" $\mathbf{B} \times \nabla \mathbf{B}$ ”) and the poloidal " $\mathbf{E} \times \mathbf{B}$ " particle drift [7].

In this paper, we review the most recent results of DN studies at DIII-D and show that variation in the magnetic balance affects other aspects of tokamak operation, such as the divertor recycling, the divertor particle flux profiles, the core electron density, and the plasma energy confinement time. In Section 2, we describe the experimental approach. In Section 3 we present our data, and in Section 4, we discuss these results. 


\section{EXPERIMENTAL CONDITIONS}

Three examples of the DN and SN shapes under consideration are shown in Fig. 1 (a) lower SN, (b) DN, and (c) upper SN. The experimental conditions were (1) ELMing $\mathrm{H}$-mode energy confinement, (2) no active particle pumping, and (3) sawtooth activity. Plasma parameters are denoted in the caption of Fig. 1.

Each discharge was started in the DN shape. During the discharge the magnetic balance was ramped to a new value and maintained at that value to allow sufficient time for equilibration of the core and scrapeoff layer (SOL) plasmas (i.e., $\approx 1.0 \mathrm{~s}$ or roughly 5-6 energy confinement times of the core plasma).
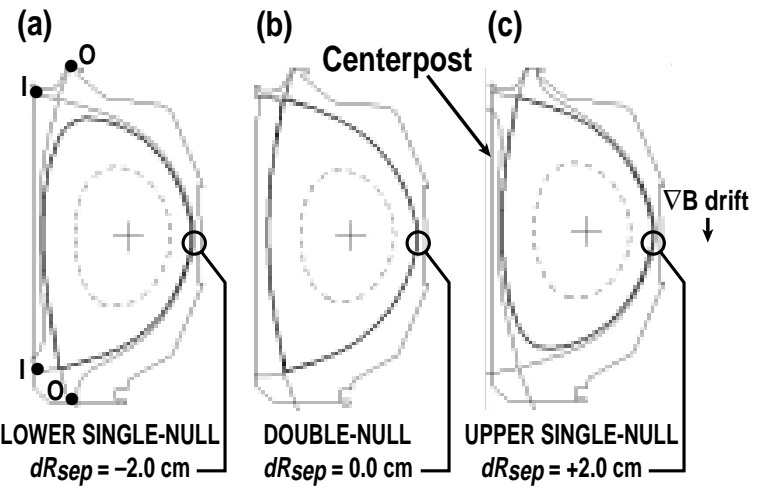

Fig. 1. Three of the magnetic flux geometries used in this study: (a) lower single-null (LSN), (b) double-null (DN), and (c) upper single-null (USN). The primary separatrix (thicker curve) and the secondary separatrix (thinner curve) are shown. The solid circles in (a) denote the inner (I) and outer (O) divertor targets; arrays of Langmuir probes are installed in the graphite tiles at each of these locations, except for the lower inboard target. The range in dRsep considered in this experiment is $-2 \mathrm{~cm} \leq \mathrm{dRsep} \leq+2 \mathrm{~cm}$. Other parameters are: $\mathrm{IP}=1.3 \mathrm{MA}, \mathrm{B}_{\mathrm{T}}=2.0 \mathrm{~T}, \mathrm{P}_{\mathrm{INPUT}}=5 \mathrm{MW}$, and $\mathrm{q} 95=4.2-4.6$.

The vacuum vessel near the upper and lower divertor is not identical: the upper divertor structure has more closure than the lower divertor structure (Fig. 1). For this reason, after running our shots with the toroidal field in one direction, we repeated the experiment with the toroidal field in the other direction. For the results reported in this paper, it is our assessment that that difference in upper and lower divertor closure played only a marginal role.

In order to quantify the divertor magnetic balance, we introduce the quantity dRsep as $\left[R_{\text {upper }}-R_{\text {lower }}\right]$, where $R_{\text {upper }}$ is the radius of the upper divertor separatrix flux at the outer midplane and $\mathrm{R}_{\text {lower }}$ is the radius of the lower divertor separatrix flux surface at the outer midplane. An example of a lower SN shape is shown in Fig. 1(a), where $R_{\text {upper }}<R_{\text {lower }}$ and dRsep is approximately $-2.0 \mathrm{~cm}$. The plasma cross-sections shown in Fig. 1(a) and Fig. 1(c) give rise to "well-defined" SNs in which the scrape-off layer widths of the parallel heat flux and electron temperature [2] are 2-4 times smaller than the absolute magnitude of dRsep. 


\section{RESULTS}

\subsection{Core plasma behavior}

Both the normalized pedestal electron density $\mathrm{n}_{\mathrm{e}, \text { ped }} / \mathrm{n}_{\mathrm{GW}}$ (where $\mathrm{n}_{\mathrm{GW}}$ is the Greenwald density parameter [8]) and plasma stored energy $\mathrm{W}_{\mathrm{T}}$ were sensitive to magnetic balance near the DN shape. Figure 2 shows the dependence of the quantities on dRsep with the $\mathbf{B} \times \nabla \mathrm{B}$ ion drift toward the lower divertor. Values were measured at the seven timeslices shown by the dots. Pedestal density and stored plasma energy $\mathrm{W}_{\mathrm{T}}$ were insensitive to changes in dRsep between DN and lower SN plasmas [Fig. 2 (b,c)]. However, as the shape changes from $\mathrm{DN}$ to upper $\mathrm{SN}, \mathrm{n}_{\mathrm{e}, \text { ped }} / \mathrm{n}_{\mathrm{GW}}$ and $\mathrm{W}_{\mathrm{T}}$ decreased $\approx 20 \%-30 \%$. The density in the interior of the core plasma also decreased by about the same amount. Pedestal electron temperature $T_{e}$, PED was much less sensitive to changes in dRsep [Fig. 2(d)], and this insensitivity was also observed in the electron and ion profiles. Thus, the decrease in $\mathrm{W}_{\mathrm{T}}$ was mostly due to the decrease in core density.

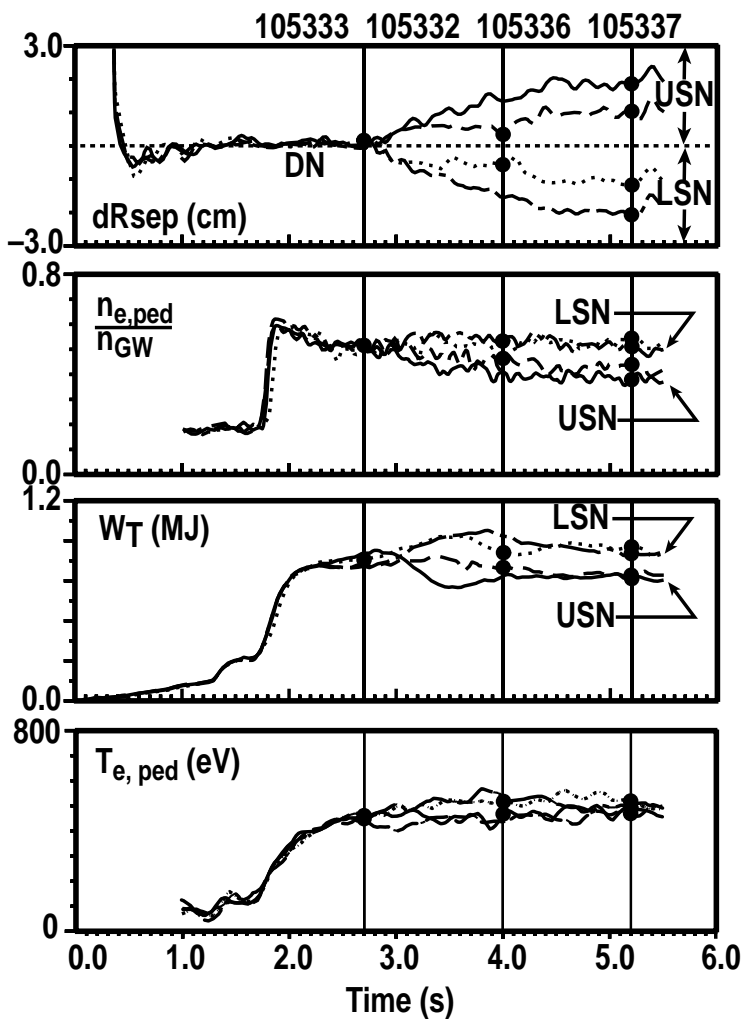

Fig. 2. The sensitivity of edge and global parameters to changes in magnetic balance. (a) The solid circles on the traces of dRsep denote the times at which data was taken. Positive values of dRsep denote upper single-null (USN) cases, and negative values denote lower singlenull (LSN) cases; dRsep $=0$ is the double-null (DN) case. (b) $\mathrm{n}_{\mathrm{e}, \mathrm{ped}} / \mathrm{n}_{\mathrm{GW}}$ is the pedestal electron density normalized to the Greenwald density parameter [8]. (c) $\mathrm{W}_{\mathrm{T}}$ is the stored plasma energy. (d) $\mathrm{T}_{\mathrm{e}}, \mathrm{PED}$ is the pedestal electron temperature.

When the $\mathrm{B}_{\mathrm{T}}$-direction was reversed, the changes in $\mathrm{n}_{\mathrm{e}}$,ped and $\mathrm{W}_{\mathrm{T}}$ also reversed and by virtually the same magnitudes, implying that difference in the closure of the two divertors was not the determining factor. If we combine both data sets and plot $n_{e, P E D}$ as a function of the absolute value of dRsep and differentiate only by whether the $\mathbf{B} \times \nabla \mathbf{B}$ is toward or away from the dominant $\mathrm{X}$-point, it is clear that most of the change in $\mathrm{n}_{\mathrm{e}, \mathrm{PED}}$ occurs over a dRsep range of about one centimeter (Fig. 3). 


\subsection{Recycling behavior}

Recycling was strongly dependent on magnetic balance. Recycling radiation $\left(D_{\alpha}\right)$ at the four possible divertor targets [see Fig. 1(a)] is shown for the case where the $\mathbf{B} \times \nabla$ $B$ drift direction was toward the lower divertor (Fig. 4). Figure 4 indicates that for the DN plasma shape the recycling is stronger near the outboard divertor targets than the corresponding inboard targets and weakest at the inboard target opposite the direction of the $\nabla$ B drift.

Similar trends were clear when the direction of $\mathrm{B}_{\mathrm{T}}$ was reversed, although the absolute values of the recycling radiation may have been affected somewhat by divertor closure.

\subsection{Particle flux at the divertor targets}

The particle flux profiles at the inboard targets were much more sensitive to changes in magnetic balance than the particle flux profiles at the outer divertor target. We compare the particle flux profiles at the inboard and outboard divertor targets for both DN and upper SN cases (Fig. 5); the $\mathbf{B} \times \nabla \mathrm{B}$ drift was directed toward the upper divertor. Under these conditions both the upstream edge density and temperature were relatively unaffected by changes in magnetic balance in

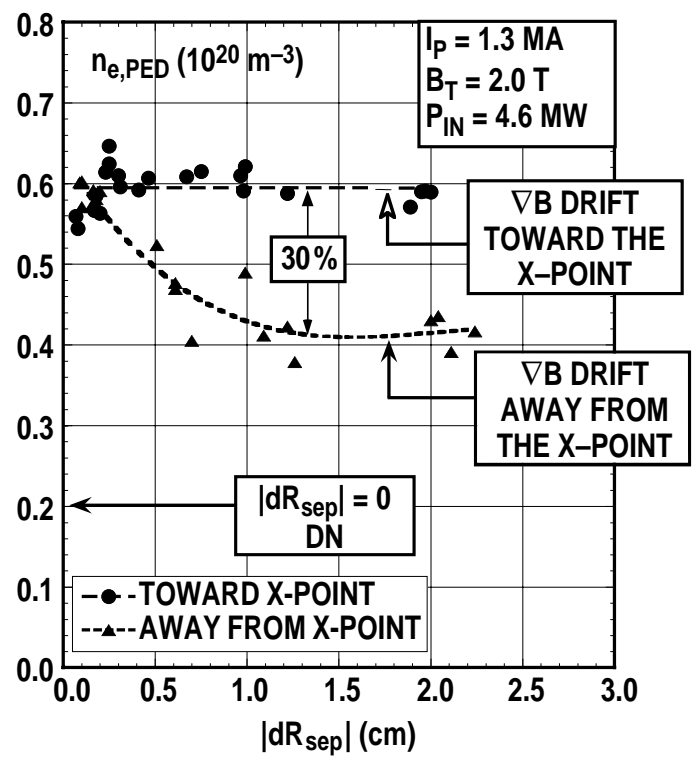

Fig. 3. The pedestal density is plotted against the absolute value of dRsep to form a composite data set for both $\mathrm{B} \times \nabla \mathrm{B}$ cases described in text.

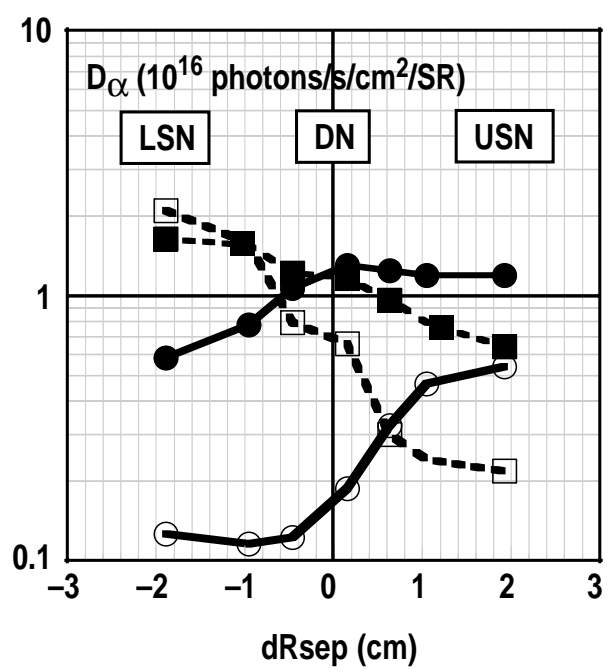

Fig. 4. Recycling $\left(D_{\alpha}\right)$ radiation at each of the four divertor targets is shown as a function of dRsep. The $\mathrm{B} \times \nabla \mathrm{B}$ direction is toward the lower divertor. The open circles $(\mathrm{O})$ denote the upper inner divertor target, the solid circles $(\bullet)$ the upper outer target, the open squares (c) the lower inner target, and the solid squares $(\boldsymbol{\square})$ the lower outer target.

the dRsep range considered (i.e., $+0.1 \mathrm{~cm}$ to $+2.1 \mathrm{~cm}$ ). The peak particle flux was $4-5$ times lower at the upper inboard target of the DN than for the $\mathrm{SN}$, and its profile in the SN case was broader. While particle flux at the inboard target was sensitive to changes in magnetic balance, both the peak particle flux and particle scrape-off width $(\approx 0.6 \mathrm{~cm})$ at the outboard divertor target were relatively insensitive for $\mathrm{dRsep}=(0.1-2.1) \mathrm{cm}$. 
(a) dRSEP $=+0.1 \mathrm{~cm}$

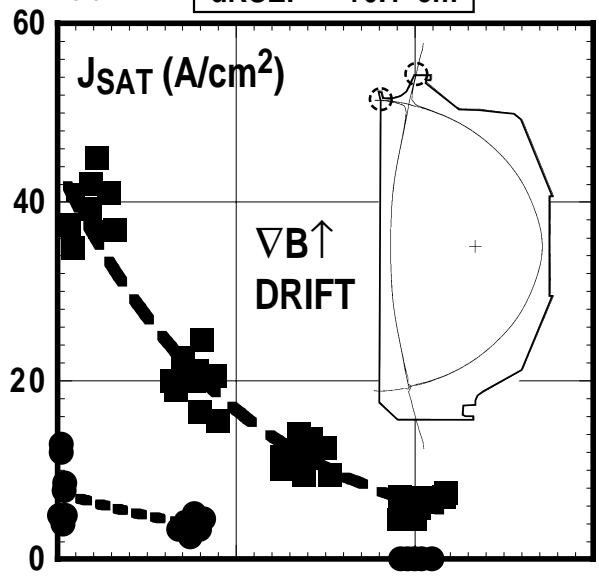

(b)

dRSEP $=+2.1 \mathrm{~cm}$

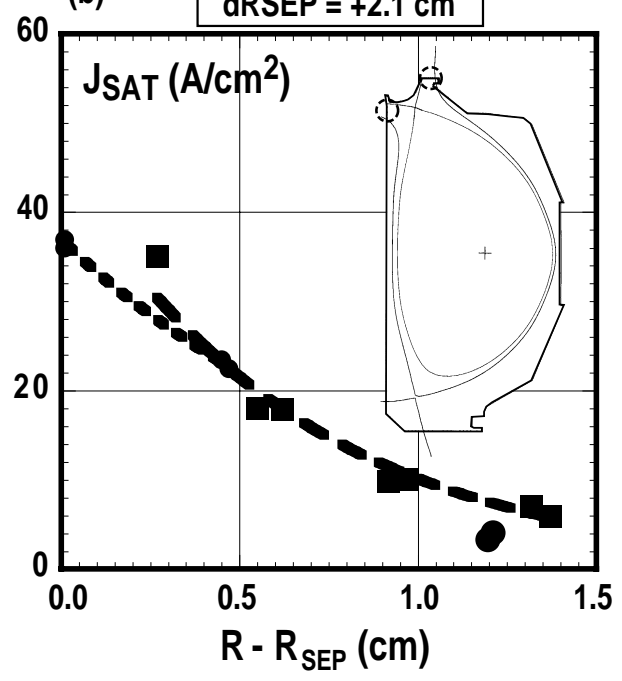

Fig. 5. The particle flux as a function of distance from the separatrix (R-RSEP) at the upper inner divertor target $(\bullet)$ and at the upper outer divertor target (ם) are shown for (a) a near-balanced DN case and (b) an upper SN case $(\mathrm{dRsep}=+2.1 \mathrm{~cm})$. The $\mathbf{B} \times \nabla \mathrm{B}$ drift was toward the upper divertor. Particle fluxes are based on Langmuir probe measurements. 


\section{DISCUSSION}

In a symmetric (magnetically balanced) DN, isolation of the inboard separatrix from the outboard separatrix affected the particle flux at the inboard target $\left(\Gamma_{\mathrm{IN}}\right)$ much more than the particle flux at the outboard divertor target $\left(\Gamma_{\text {OUT }}\right)$. The relative insensitivity of $\Gamma_{\text {OUT }}$ to changes in the magnetic balance suggests that particle loss through the separatrix on the inboard side was not a major contributor to $\Gamma_{\text {OUT }}$. However, the relatively low $\Gamma_{\text {IN }}$ in DN and the much higher $\Gamma_{\text {IN }}$ when the inboard and outboard SOLs were magnetically connected indicate the importance of the particle loss through the outboard separatrix to $\Gamma_{\text {IN }}$ for $S N$. Taken together, the particle loss through the outboard separatrix is considerably higher than the particle loss through the inboard separatrix.

We estimate the ratio of particle loss through the outboard separatrix to that through the inboard separatrix to be roughly 3-4, based on (1) the radial gradients in density on the outboard side being about twice that of the inboard side, (2) the surface area on the outboard side of the plasma being approximately 1.7 times that on the inboard side, (3) the particle diffusivity being poloidally uniform. Other processes might also increase the particle loss ratio, as (1) ELMing which expels particles almost solely through the outboard side [9] and (2) turbulent transport on the outboard side $[10,11]$. With respect to the latter, "bad" curvature on the outboard side of the $\mathrm{X}$-points and "good" curvature on the inboard side can increase the particle flow loss through the outboard side relative to that through the inboard side.

While the density at the inboard midplane SOL cannot be measured directly, we may infer what this density might be, based on (1) the measured density and heat flux profiles at the divertor targets, (2) equilibrium geometry, and (3) application of the simple two-point model of the SOL [12]. The "line-averaged density" at the inboard midplane from R-R $\mathrm{R}_{\text {sep }}=0$ to $1 \mathrm{~cm}$ of the SOL is found to be roughly 2-3 times higher in the SN case than in the DN case.

The "asymmetric" distribution of the recycling at each of the divertor targets was reproduced in both $\mathbf{B} \times \nabla \mathbf{B}$ drift directions. Modeling of the SOL with UEDGE has shown that these asymmetries were largely driven by the $\mathbf{E} \times \mathbf{B}$ poloidal drift; several of the main assumptions are listed in the caption to Table 1. For the $\mathbf{B} \times \nabla \mathbf{B}$ downward case, the $\mathbf{E} \times \mathbf{B}$ drift transports ions through the private flux region (PFR) from the outer plate to the inner plate in the lower divertor, thus increasing the recycling at the inboard plate. The origin of the electric field (E) arises mainly from the radial gradient in the electron temperature with respect to the flux surfaces in the PFR and its direction is always into the PFR. In the upper divertor, the $\mathbf{E} \times \mathbf{B}$ drift transport ions from the inner plate to the outer plate, thus increasing recycling at the outboard plate. The 
measured in/out and up/down recycling ratios for the DN shown in Fig. 4 compare reasonably with the UEDGE predictions. See Table 1.

Table 1. Comparison of measured recycling ratios (Fig. 4) with UEDGE predictions where the $B \times \nabla B$ drift direction is toward the lower divertor

\begin{tabular}{lcccc}
\hline & DUP-OUT/DUP-IN & D LOW-OUT/D $_{\text {LOW-IN }}$ & DUP-IN/D $_{\text {LOW-IN }}$ & DUP-OUT/D $_{\text {LOW-OUT }}$ \\
\hline Experiment & 6.8 & 1.8 & 0.3 & 1.1 \\
UEDGE & 4.7 & 1.3 & 0.4 & 1.5 \\
\hline
\end{tabular}

For the simulations UEDGE [4] used $\mathrm{H}$-mode values for particle and energy diffusivities: $\mathrm{D}_{\mathrm{i}}$ $=0.25 \mathrm{~m}^{2} / \mathrm{s}$ and $\chi_{\mathrm{e}}$ and $\chi_{\mathrm{i}}=0.50 \mathrm{~m}^{2} / \mathrm{s}$. Simple "diffusive" modeling of the neutrals was used, e.g., the neutral gas diffuses due to charge-exchange on the ions, and the neutral gas and ions are assumed to have the same temperature consistent with the combined ion and neutral energy equations. The plate recycling coefficient was taken as 0.98 and the wall recycling coefficient was taken as 0.9.Particle drifts are indluded.

The behaviors of $\mathrm{n}_{\mathrm{e} \text {,ped }}$ and $\mathrm{W}_{\mathrm{T}}$ with changes in magnetic balance shows a clear dependence on the direction of the toroidal magnetic field (corresponding to different $\mathbf{B} \times \nabla \mathrm{B}$ direction). The reason for this behavior is unclear at this time. The change in the poloidal distribution of recycling with magnetic balance can imply a change in the core fueling. From UEDGE modeling, the biggest contributor to core fueling comes from the inboard plate in the $\mathbf{B} \times \nabla \mathrm{B}$ direction, even though the strongest recycling source is at the outboard target opposite the $\mathbf{B} \times \nabla \mathrm{B}$ direction. Neutrals from the inboard targets penetrate more easily because lower inboard temperatures translates to weaker ionization/attenuation rates and shorter distance from the inboard targets to the core. The recycling at the inboard targets becomes relatively weak (compared to the outboard recycling) when the $\mathbf{B} \times \nabla \mathrm{B}$ direction is opposite the main $\mathrm{X}$-point, so that net fueling of the core plasma would be reduced. Yet, if the decrease in $n_{e}$,ped were due solely to a fueling effect, then one would expect the electron temperature would increase. However, both core $\mathrm{T}_{\mathrm{e}}$-profile and $\mathrm{T}_{\mathrm{e}, \mathrm{PED}}$ are insensitive to changes in dRsep. Hence, though fueling may be a factor, other physics processes evidently are playing a role.

No evidence of MHD presence in the core (except for the sawtooth activity present in all shots) is observed. Changes in the frequency of the ELMs with magnetic balance cannot be correlated directly with the behavior of $\mathrm{n}_{\mathrm{e} \text {,ped }}$ and $\mathrm{W}_{\mathrm{T}}$. Other possibilities are under study, e.g., changes in the stability of the pedestal as a function of dRsep. 


\section{CONCLUSIONS}

Our results to-date may provide insight into the divertor requirements in future generation tokamaks. Because of the relatively low particle and power flow [2] to the inboard target(s) in $\mathrm{DN}$, there may be reduced need for heavy protective armor at the inboard targets and particle pumping from the inboard side may be unnecessary. This could result in both cost savings and simplified divertor design. Because of the relatively low density along the inboard SOL in DNs, as well as the absence of ELMing on the inboard side, the DN would allow more efficient use of the vessel volume by positioning the plasma closer to the centerpost than is possible in SNs. For the same reasons, injecting neutral gas from the inboard side may be a natural and effective way to fuel DNs in future larger tokamaks [13]. Because there could be degradation in performance if the magnetic balance of the DN plasma moves in the "wrong" direction, precise control over magnetic balance is a requirement. 


\section{REFERENCES}

[1] L.L. Lao, Y. Kamada, T. Oikawa, L.R. Baylor, K.H. Burrell, et al., Nucl. Fusion 41 (2001) 295.

[2] T.W. Petrie, C.M. Greenfield, R.J. Groebner, A.W. Hyatt, R.J. Lahaye, et. al., J. Nucl. Mater. 290-293 (2001) 935.

[3] T.W. Petrie, M.E. Fenstermacher, C.J. Lasnier, Fusion Technology, 39 (2001) 916.

[4] T.D. Rognlien, et al., Plasma Phys. 34 (1994) 362.

[5] T.D. Rognlien, G.D. Porter, D.D. Ryutov, J. Nucl. Mater. 266-269 (1999) 654.

[6] M.E. Rensink, C.J. Lasnier, T.W. Petrie, G.D Porter, and T.D. Rognlien, Contrib. Plasma Phys. 42 (2002) 181.

[7] A.V. Chankin, J. Nucl. Mater. 241-243 (1997) 199.

[8] M. Greenwald, J. Terry, S. Wolfe, et al., Nucl. Fusion 28 (1988) 2199.

[9] T.W. Petrie, J.G. Watkins, L.L. Lao, P.B. Snyder, "The Role of Magnetic Balance on the Poloidal Distribution of ELM-induced Peak Particle Flux at the Divertor Targets in DIII-D," (submitted to Phys. Rev. Lett., 2002).

[10] G.R. Tynan, "On the Origins of Tokamak Edge Turbulence and the H-mode Transition, Advanced Series in Nonlinear Dynamics," 9, World Scientific, Singapore (1995) 254.

[11] X. Xu, et al., Proc. 13th U.S. Transport Task Force Workshop, Burlington, Vermont, (April 2000) 26-29.

[12] P.C. Stangeby, "The Plasma Boundary of Magnetic Fusion Devices," Institute of Physics Publishing, (2000) 224.

[13] L.R. Baylor, T.C. Jernigan, R.J. Colchin, G.L. Jackson, T.W. Petrie, “Comparison of Fueling Efficiency from Different Fueling Locations on DIII-D," (this proceedings). 


\section{ACKNOWLEDGMENT}

Work supported by U.S. Department of Energy under Contracts DE-AC03-99ER54463, DE-AC04-94AL85000, DE-AC05-00OR22725, W-7405-ENG-48, and Grant DE-FG0395ER54294. 